\title{
Genomic Organization and Isoform-Dependent Expression Patterns of Wap65 genes in Various Tissues during Immune Challenges in the Mud Loach Misgurnus mizolepis
}

\author{
Yi Kyung Kim ${ }^{1}$, Young Sun Cho ${ }^{1}$, Sang Yoon Lee ${ }^{1}$ and Yoon Kwon Nam ${ }^{1,2 *}$ \\ ${ }^{1}$ Department of Marine Bio-Materials and Aquaculture, Pukyong National University, Busan 608-737, Korea \\ ${ }^{2}$ Center of Marine-Integrated Biomedical Technology (BK21 Plus Team), Pukyong National University, Busan 608-737, Korea
}

\begin{abstract}
Genomic organization, including the structural characteristics of $5^{\prime}$-flanking regions of two 65-kDa protein (WAP65) isoform genes associated with warm temperature acclimation, were characterized and their transcriptional responses to immune challenges were examined in the intestine, kidney and spleen of the mud loach (Misgurnus mizolepis; Cypriniformes). Both mud loach Wap65 isoform genes displayed a 10-exon structure that is common to most teleostean Wap65 genes. The two mud loach Wap65 isoforms were predicted to possess various stress- and immune-related transcription factor binding sites in their regulatory regions; however, the predicted motif profiles differed between the two isoforms, and the inflammation-related transcription factor binding motifs, such as NF- $\mathrm{BB}$ and CREBP sites, were more highlighted in the Wap65-2 isoform than the Wap65-1 isoform. The results of qRT-PCR indicated that experimental immune challenges using Edwardsiella tarda, lipopolysaccharide or polyI:C induced the Wap65-2 isoform more than Wap65-1 isoform, although modulation patterns in response to these challenges were tissue- and stimulant-dependent. This study confirms that functional diversification between the two mud loach Wap65 isoforms (i.e., closer involvement of Wap65-2 in the acute phase of inflammation and innate immunity) occurs at the mRNA level in multiple tissues, and suggests that such differential modulation patterns between the two isoforms are related to the different transcription factor binding profiles in their regulatory regions.
\end{abstract}

Key words: Misgurnus mizolepis, Wap65 isoforms, Immune challenges, Mud loach, Gene and promoter structures

\section{Introduction}

The 65-kDa protein (WAP65) is thought to play a central role in homeostatic responses and acclimation of eurythermal teleosts to warm temperatures (Kikuchi et al., 1993, 1995). Besides its essential function in thermal acclimation, this serum glycoprotein is also involved in various other cellular pathways, especially those relating to innate immunity (Sha et al., 2008). The potential role of WAP65 proteins as an immune modulator has been demonstrated in several previous studies on dynamic modulations in fish tissues during immune-stimulating challenges and/or environmental pertur- bation treatments (Aliza et al., 2008; Sha et al., 2008; Shi et al., 2010). Teleosts typically possess two functional WAP65 isoforms (WAP65-1 and WAP65-2) and previous reports have suggested that these two isoforms have been functionally diversified or subfunctionalized, where the fish WAP65-2 isoform generally has a closer orthology to human hemopexin (HPX) than WAP65-1 (Cho et al., 2012; Lee et al., 2014). Empirical mRNA expression assays in previous studies on various fishes have also indicated that Wap65-2 transcripts, rather than Wap65-1, would be preferentially modulated by immune-
(C) 2014 The Korean Society of Fisheries and Aquatic Science This is an Open Access article distributed under the terms of the Creative Commons Attribution Non-Commercial Licens (http://creativecommons. org/licenses/by-nc/3.0/) which permits unrestricted non-commercial use, distribution, and reproduction in any medium, provided the original work is properly cited.
Received 23 June 2014; Revised 09 August 2014

Accepted 18 August 2014

*Corresponding Author

E-mail: yoonknam@pknu.ac.kr 
relevant challenges. However, such isoform-specificity is not found in all fish species, and contradictory or inconsistent patterns depending on tissue type have also been reported in several fish species (Kikuchi et al., 1997; Hirayama et al., 2004; Sarropoulou et al., 2010).

The mud loach (Misgurnus mizolepis; Cypriniformes) is an aquaculture-relevant species with increasing market demand in Korea. In addition to its commercial importance, this fish species has also received considerable attention as an experimental organism in genetic and genomic studies, given its optimal traits for a model organism such as rapid and transparent embryonic development, high fecundity and well-established techniques for chromosome-set manipulation and transgenesis (Kim et al., 1994; Nam et al., 2011). Furthermore, the mud loach is a truly eurythermal teleost and tolerant to temperatures ranging from near zero to over $30^{\circ} \mathrm{C}$, suggesting that this species could be a good model for studying WAP 65 proteinmediated orchestration of thermal acclimation and innate immunity. We recently isolated two mud loach Wap65 cDNA isoforms showing the liver-predominant expression pattern, and suggested the mud loach Wap 65 paralogs have potentially undergone functional partitioning with differential involvement in immune-related cellular pathways in the liver (Cho et al., 2012). However, information on the differential expression pattern of mud loach Wap65 isoforms remains limited to only the liver, and their responses in other immune-related organs - such as the kidney and spleen - have not been explored. Despite its importance, no information is available on the genomic characteristics of the Wap 65 isoform genes in the mud loach, particularly regarding their promoter structures. As such, the objective of this study was to characterize the genomic organization, including the 5 '-upstream regulatory regions, of mud loach Wap65 isoform genes, and to scrutinize the mRNA expression of the two isoforms in three non-liver organs (intestine, kidney and spleen) in response to various immune-related challenges.

\section{Materials and Methods}

\section{Molecular cloning of genomic gene and 5 '-upstream regulatory region}

The mud loach genomic DNA library was screened using the filter hybridization method to isolate the genomic copies of Wap65 isoforms. Approximately $5 \times 10^{6}$ genomic clones were filter-hybridized with a digoxigenin-labeled cDNA probe of each Wap65 isoform using the DIG DNA Labeling and Detection Kit according to the manufacturer's instructions (Roche Applied Science, Mannheim, Germany). After three rounds of successive screening, positive clones were selected for each Wap65 isoform and subjected to subcloning into pBluescript KS phagemid vectors (Agilent Technologies, Inc., Santa Clara, CA, USA). This was followed by restriction enzyme mapping and sequencing analysis, during which the orientation of subclones for each Wap 65 isoform was determined and the correct joining between subclones was confirmed by PCRisolation and sequencing analysis of each junction fragment. Based on the primary draft of contig sequence for each Wap 65 isoform, several overlapping fragments (each ranging from 3 to $5 \mathrm{~kb}$ in length) of the contig of each Wap65 isoform were reisolated using PCR from purified mud loach genomic DNA, cloned into pGEM-T easy vectors (Promega, USA) and sequenced in both directions. If needed, one or two rounds of genome walking to the 5 -flanking region were also performed using the Genome Walker Universal Kit (Clontech Laboratories, Inc., Mountain View, CA, USA) to obtain a sufficient length of $5^{\prime}$-upstream regulatory region. Following this, the representative genomic sequence of each Wap65 isoform was confirmed by PCR isolation of overlapping fragments and direct sequencing analysis of the amplified PCR products.

The genomic nucleotide sequences of the two isoform genes are deposited in GenBank (http://www.ncbi.nlm.nih. gov) under accession codes $\underline{\mathbf{K M 2 0 9 2 0 3}}$ (for Wap65-1 genomic gene) and KM209204 (for Wap65-2). The coding sequence of each genomic gene was confirmed based on the comparison with counterpart its cDNA sequence (JN230714 for Wap65-1 and JN230715 for Wap65-2). For each isoform, exon-intron boundary regions and genomic organization were compared with those of other fish Wap65 genes that were either retrieved from the NCBI GenBank or deciphered from the Ensembl Genome Browser (http://www.ensembl.org/index.html). The 5 '-flanking upstream region sequence of each Wap65 isoform was subjected to transcription factor (TF) binding sites using the TFSEACRCH (ver. 1.3; http://www.cbrc.jp/research/db/ TFSEARCH.html).

\section{Fish specimen and experimental challenges}

Experimental mud loach specimens used in this study were obtained from a laboratory stock maintained at the Experimental Fish Culture Station, Pukyong National University, Busan. Twelve individuals (average body weight $[\mathrm{BW}]=10.5 \mathrm{~g}$ ) were allocated to one of eight 60 - $\mathrm{L}$ water-recirculating tanks and acclimated to the tank conditions for 2 weeks prior to experimental immune challenges. Fish were fed with commercial pellets for carp ( $45 \%$ crude protein; Woosung Feed Corp., Korea) four times per day during the acclimation period. The temperature was maintained at $24 \pm 1^{\circ} \mathrm{C}$ throughout the period and the water exchange rate was $20 \%$ per day. After the acclimation period, fish were challenged with Edwardsiella tarda (FSW910410; ET), lipopolysaccharide (LPS; Escherichia coli 0111:B4, Sigma-Aldrich, St Louis, MO, USA) or polyI:C (Sigma-Aldrich, St Louis, MO, USA). For the ET-challenge, fish ( $n=12$ per group) were given an intraperitoneal (IP) injection of $1 \times 10^{6}$ ET cells suspended in $200 \mu \mathrm{L}$ of PBS (pH 6.8). For the LPS-challenge, fish were given an IP injection of PBS-suspended LPS at the dose levels of 2 or $5 \mu \mathrm{g} / \mathrm{g} \mathrm{BW}$. 
On the other hand, the polyI:C-challenged groups $(n=12$ per group) were prepared by injecting the PBS-suspended polyI:C at dose levels of 10 or $50 \mu \mathrm{g} / \mathrm{g}$ body weight. The injection volume was also $200 \mu \mathrm{L}$ for LPS and polyI:C challenges. Two PBS-injected groups $(n=12$ each for 24 and $48 \mathrm{~h}$ post injection groups) were then selected as non-challenged control groups. From the ET-challenged groups, eight randomly chosen individuals were sampled at 24 and $48 \mathrm{~h}$ post injection, while fish ( $n=8$ per tank) were obtained at $24 \mathrm{~h}$ post injection from the LPS- and polyI:C-challenged groups. At each time point of sampling from the challenged groups, the same number of non-challenged control fish was also obtained from the PBS-injected group. Three tissues (intestine, kidney and spleen) were surgically removed from each fish for RNA isolation and gene expression assay.

\section{Nucleic acid preparation and qPCR analysis}

Total RNA was purified using either TriPure Reagent (Roche Applied Science, Germany) or RNeasy Midi Kit (Qiagen, Hilden, Germany), depending on tissue type, according to the manufacturer's instructions. An aliquot $(2 \mu \mathrm{g})$ of total RNA was reverse transcribed into cDNA using the Omniscript Reverse Transcription Kit (Qiagen, Germany). During the RT-reaction, a mud loach 18S rRNA reverse primer (ML18SRV: 5'-CAAGAATTTCACCTCTAGCGGC-3'; $0.1 \mu \mathrm{M}$ final concentration) was included to prepare $18 \mathrm{~S}$ rRNA normalization control for each sample. Mud loach Wap65-1 (amplicon size $=303 \mathrm{bp})$ and Wap65-2 (amplicon size $=267 \mathrm{bp})$ isoforms were amplified by using the following primer pairs: qmlWAP01-1F (5'-GGACCCAATGGTGTGACTA-3')/1R (5'-GATACATCTGAGCAGAAC-3') and qmlWAP02-1F (5'-TGCAGCCCATTACACTCTCA-3')/1R (5'-CCAAAGTCATAGTACTCTGG-3'). The normalization control (18S rRNA; amplicon size $=274 \mathrm{bp}$ ) was amplified qML18S $1 \mathrm{~F}$ (5'-ACCCATTGGAGGGCAAGTCT-3')/1R (5'-CCTAGCTGAGATATTCAGGC-3'). Quantitative PCR amplification was performed with the iCycler Real-Time Optical Module (Bio-Rad Laboratories, USA) and 2X iQ SYBR Green Supermix (Bio-Rad Laboratories, USA), and thermal cycling conditions described in Cho et al. (2012). Based on the standard curve for each gene (Wap65-1, Wap65-2 and 18S rRNA), PCR efficiency ranging $96-99 \%$ was confirmed and the expression levels of Wap65 isoforms in each sample were normalized to the level of 18S rRNA and the expression levels of the stimulated groups (ET-, LPS- and polyI:C-challenged) relative to the non-stimulated control group (PBS-injected); this was calculated as a fold-difference according to the $\Delta \mathrm{Ct}$ method (Schmittgen and Livak, 2008). Three replicate examinations were conducted for each cDNA sample in an independent manner, and differences in expression levels were assessed using Student's t-test or ANOVA followed by Duncan's multiple range tests at the level of $P=0.05$.

\section{Results and Discussion}

Fragments $(9.26$ and $18.99 \mathrm{~kb})$ for the mud loach Wap65-1 and Wap65-2 isoform genes, respectively, were obtained by genomic cloning. The Wap65-1 gene consisted of $4.62 \mathrm{~kb}$ of the 5' - flanking region upstream from the ATG translation initiation codon, 10 exons $(65,29,150,158,154,213,102$, 125,148 and $230 \mathrm{bp}$ for exons I to X) interrupted by 9 introns (364, 141, 486, 360, 633, 96, 112, 76, and $99 \mathrm{bp}$ for introns I to IX) and $897 \mathrm{bp}$ of $3^{\prime}$ - flanking region including the 322 bp of transcribed $3^{\prime}$-untranslated region (UTR) present in its cDNA counterpart. The length from ATG to stop codon in the Wap65-1 isoform was $3.74 \mathrm{~kb}$. Conversely, the mud loach Wap65-2 isoform comprised the 3.35-kb 5 '-flanking region, a $15.45-\mathrm{kb}$ fragment spanning ATG to the stop codon, and 193 bp of the 3'-UTR. The Wap65-2 gene also revealed a 10-exon structure $(65,23,126,158,154,216,93,131,148$ and $227 \mathrm{bp})$ interrupted by 9 introns (463, 4746, 102, 95, 4958, 118, 429, 145 and $3056 \mathrm{bp}$ ). Both isoform genes consistently showed the conserved, canonical GT/AG exon-intron boundary rule in all junction regions, and presumed coding sequences in each genomic isoform were well-matched with those of the corresponding cDNA. The length of each exon was similar between the Wap65-1 and Wap65-2 isoforms, resulting in similar total lengths of coding exon regions (1.37 kb for Wap65-1 and 1.34 $\mathrm{kb}$ for Wap65-2). However, intronic lengths were highly variable, especially for notably longer introns in the Wap65-2 isoform $(4.75 \mathrm{~kb}$ for intron $2,4.96 \mathrm{~kb}$ for intron 5 and $3.06 \mathrm{~kb}$ for intron 9) compared to the corresponding introns (141, 633 and $99 \mathrm{bp}$, for intron 2, 5 and 9, respectively) in the Wap65-1 isoform. As shown in Fig. 1, the 10-exon structure of both Wap65 isoform genes is well conserved in most, but not all, teleostean species belonging to a wide array of taxonomic positions, suggesting that the these two isoforms evolved from a common ancestral form. However, it should also be noted that the olive flounder (Paralichthys olivaceus; Pleuronectiformes) (Kim et al., 2013) and one Cichlidae species (Maylandia zebra; Cichliformes) have only nine exons in their Wap65-1 isoform. In the olive flounder, the large exon $\mathrm{V}$ of the Wap65-1 isoform was believed to be a combined exon that corresponds to exons $\mathrm{V}$ and VI of other teleostean Wap65-1 genes (Kim et al., 2013). In the case of M. zebra, the exon-shuffling pattern is unclear due to unfinished sequence information on the Wap65 loci. Given that the information on genomic organizations of both Wap65 isoforms from a given species is limited to a few fish species, it is not known whether this inter-isoform difference in exon-intron organization is specific to certain lineages such as Pleuronectiformes and Cichliformes. However, overall genomic organization data suggest that the teleost Wap65 gene may have undergone exon-shuffling during evolution in certain lineages or species following the acquisition of the Wap65 paralogs in teleost genomes. Previous molecular phylogenetic analysis suggests the Wap65 paralogue genes may have been acquired from the lineage-specific genome-wide duplica- 


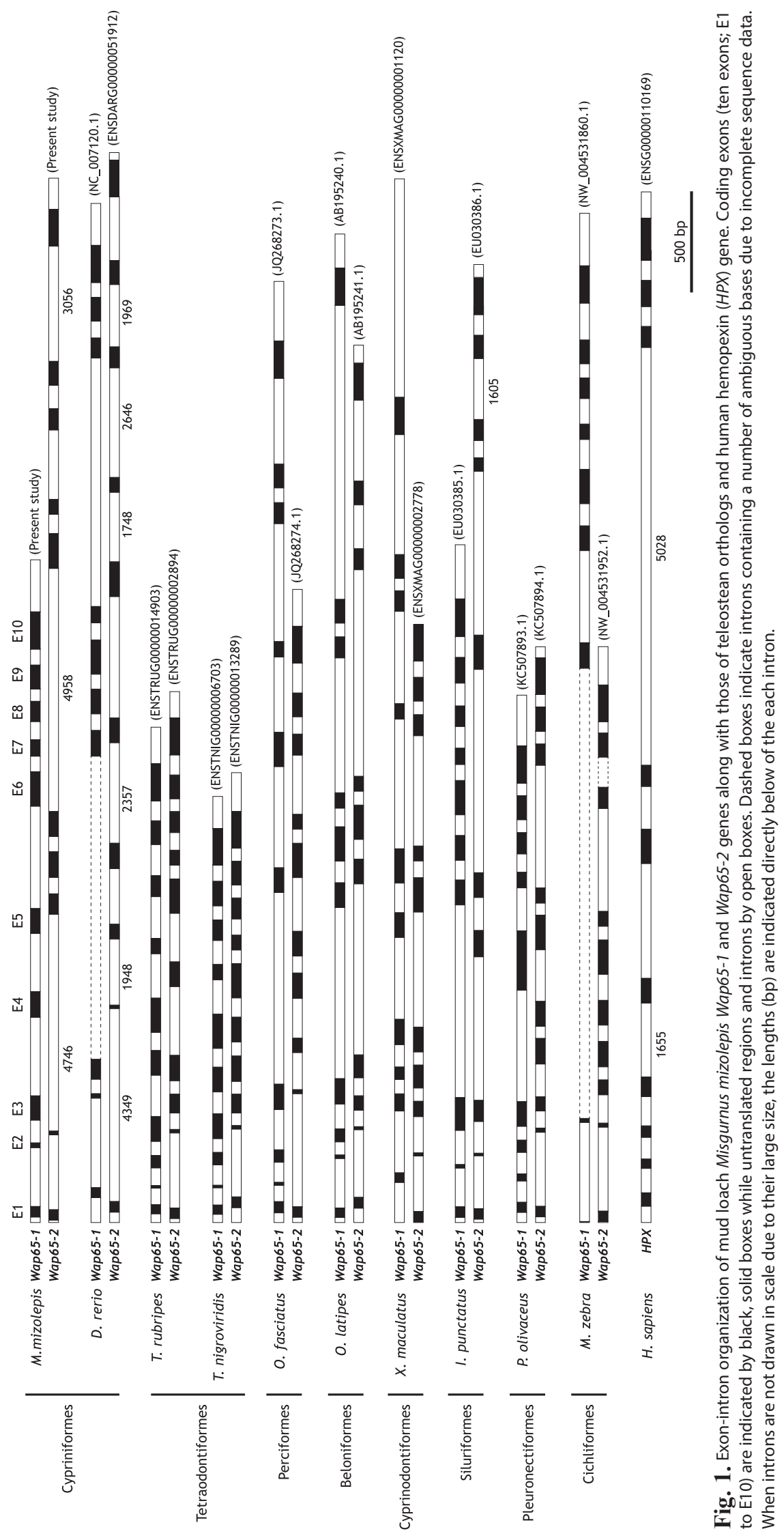



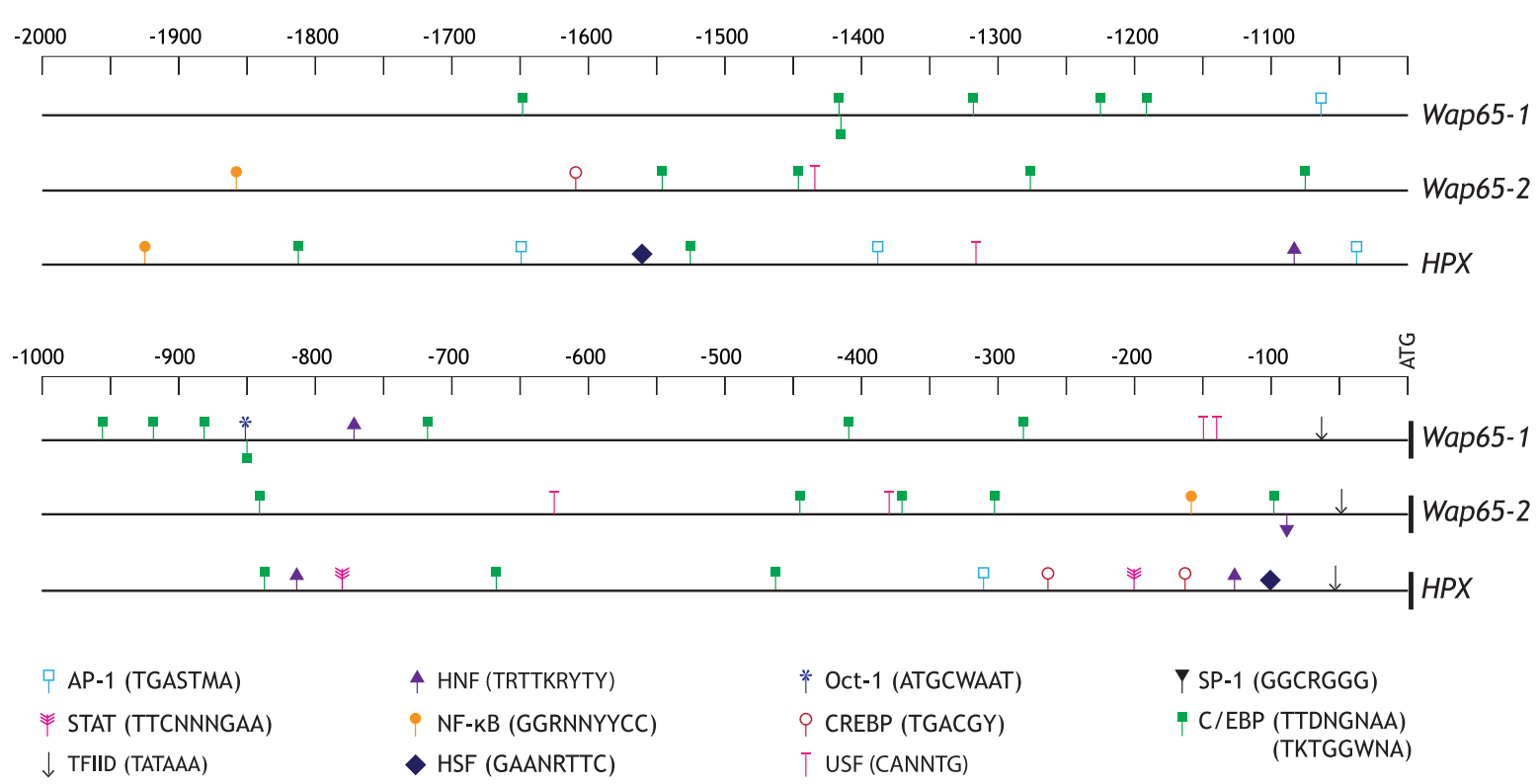

Fig. 2. Comparison of transcription factor binding motifs in the regulatory regions of mud loach Misgurnus mizolepis Wap65-1, Wap65-2 and human HPX gene. The 2-kb 5'-upstream region from ATG initiation codon of each Wap65 isoform was bioinformatically assessed based on TFSEARCH (http://www.cbrc. jp/research/db/TFSEARCH.html).

tion of ray-finned fish (Dooley et al., 2010; Sarropoulou and Fernandes, 2011); thus, such an inter-isoform difference in exon-intron organization may be a more recent lineage- or species-specific event. Besides the difference in exon-intron organization, the Wap65 gene is also known to have undergone species-specific gene duplication (i.e., intra-chromosomal amplification), resulting in gene copy number variability among species as evidenced by the four tandem copies of the Wap65-1 gene (whereas only one copy of Wap65-2 isoform) in the catfish (Ictalurus punctatus) genome (Sha et al., 2008).

Two kilobases of DNA upstream from the ATG codon of each mud loach Wap65 isoform were bioinformatically analyzed, and both isoforms represent various motifs/elements targeted by TFs during stress response and/or innate immunity processes (Fig. 2); they include activating protein-1 (AP-1; consensus sequence $=$ TGASTAM), CCAAT-enhancer binding protein (C/EBP; TTDNGNAA or TKTGGWNA), cAMPresponse element binding protein (CREPB; TGACGY), octamer-binding transcription factor-1 (Oct-1; ATGCWAAT), and/or upstream stimulatory factor (USF; CANNTG). These common factors have frequently been reported to modulate the transcription of various genes involved in host defense systems (Truksa et al., 2007; Cho et al., 2009; Nam et al., 2011). Oct-1, a member of the POU domain transcription factor family, has also been shown to exert multiple functions as a sensor for metabolic and stress signals (Wang and Jin, 2010). In the comparison between the two mud loach isoforms, only the Wap65-1 isoform contained AP-1 and Oct-1 binding sites as well as greater numbers of C/EBP sites than the Wap65-2 isoform. Conversely, the Wap65-2 regulatory region displayed two nuclear factor kappa B (NF-кB; GGRNNYYCC) sites; one was in the proximal region (-160 bp from ATG) and the other in the distal region (-1920 bp), which was not predicted within the 2-kb proximal upstream region of the Wap65-1 isoform. In addition, the CREBP motif was also exclusively predicted in the Wap65-2 isoform. Considering that NF-кB is a key player in innate immune defense systems, especially the Toll signaling pathway (Hayden and Ghosh, 2004; Cho et al., 2009), the exclusive prediction of NF-KB in the Wap65-2 promoter suggests that Wap65-2 isoform to be more closely related to inflammation-mediated modulation than the Wap651 isoform. The presence of cytokine responsive and/or stressrelated motifs has also been reported in Wap65 genes in a few species, although comparative examinations of the two isoforms within a single fish species are limited to a few fish species (Hirayama et al., 2003; Nakaniwa et al., 2005; Sha et al., 2008). Further comparison of TF-binding motifs in mud loach Wap65 isoforms with those in the human HPX showed no apparent synteny. However, only Wap 65-2 and HPX promoters were expected to possess NF-KB and CREBP sites, whereas the Oct-1 sites predicted in Wap65-1 was identified in neither the Wap65-2 nor HPX promoter. Similar findings have been reported in rockbream (Oplegnathus fasciatus) Wap65 isoform genes (Lee et al., 2014).

As determined by qRT-PCR, the transcriptional responses of the mud loach Wap65 gene were variable depending on the isoform, tissue, and type of stimulant (Fig. 3). Doses of immune-stimulating agents (ET and LPS) used in this study 

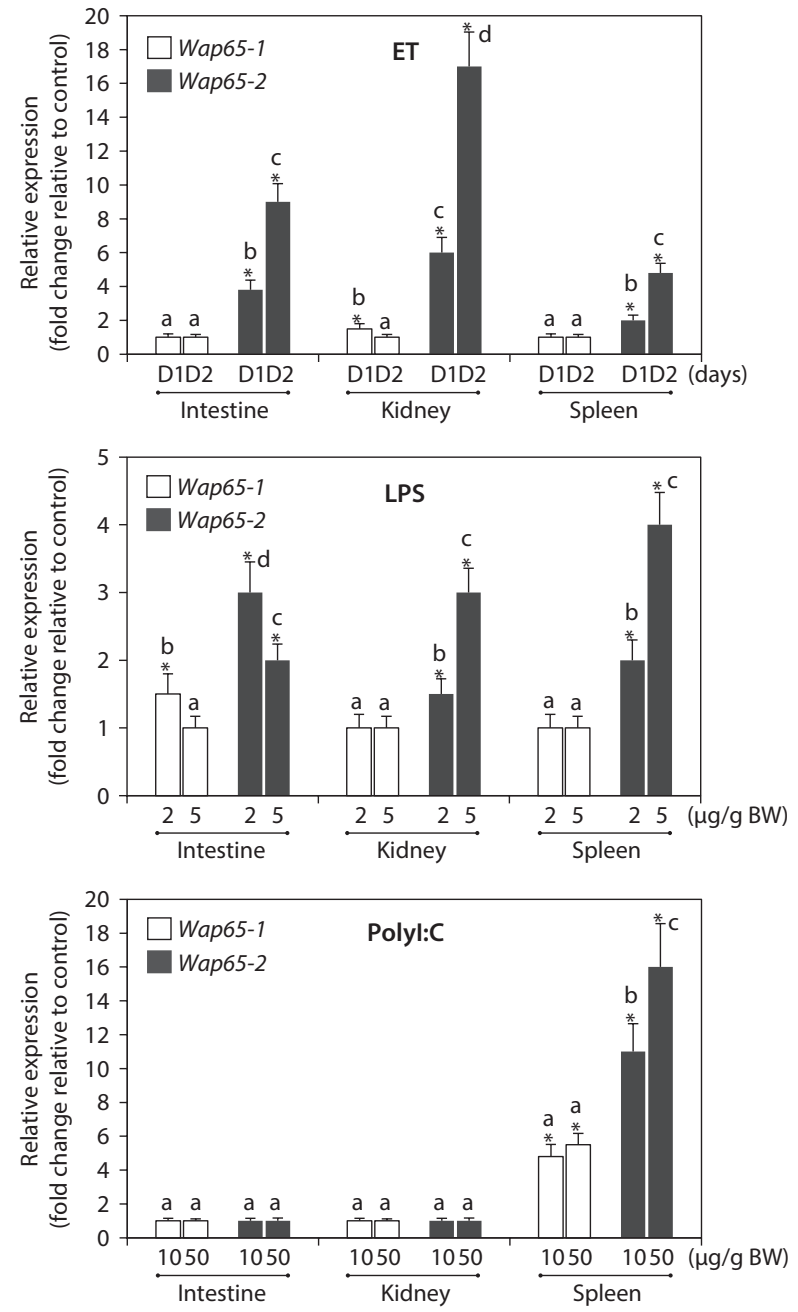

Fig. 3. Differential mRNA expression of mud loach Misgurnus mizolepis, Wap65-1 and Wap65-2 isoforms in response to Edwardsiella tarda (ET), LPS or polyl:C challenges in the intestine, kidney and spleen tissues, based on qRT-PCR. ET-challenged group was assessed at 1 (D1) and 2 (D2) days after challenge, while groups challenged with LPS ( 2 or $5 \mu \mathrm{g} / \mathrm{g}$ body weight [BW]) and polyl:C (10 or $20 \mu \mathrm{g} / \mathrm{g} \mathrm{BW}$ ) at $24 \mathrm{~h}$ post challenge. Mean \pm SDs with different letters $(a-d)$ within a given tissue are significantly different based on ANOVA at $P=0.05$. Asterisks indicate the means different from the values observed in the non-challenged control groups $(P<0.05)$.

have been confirmed to induce acute immune responses in various tissues of this species, as evidenced by the differential induction of known immune-relevant genes (Nam et al., 2011). In the ET challenge, the Wap65-1 isoform showed little modulation in response to bacterial injections regardless of tissue type and duration, with the exception of a small but statistically significant increase (1.5-fold relative to PBS control) in the kidney at $24 \mathrm{~h}$ post-injection (day 1); however, this effect was diminished at $48 \mathrm{~h}$ post-injection (day 2). In contrast, the Wap65-2 isoform exhibited significant upregulation in response to ET injection in all three tissues, from 2 to 17-fold compared to the PBS-injected groups. Furthermore, the level of expression induction was more significant at $48 \mathrm{~h}$ post-injection than at $24 \mathrm{~h}$ in all three tissues, suggesting that the host-defense role (s) of the Wap 65-2 isoform may increase in importance as infection progresses and inflammation intensifies. The induction of Wap65-2 expression was higher in the kidney (17-fold at day 2) than the intestine or spleen. Preferential induction of Wap65-2 was also examined in the LPSchallenged groups, although the tissue-dependency observed following ET challenge was not reproducible in this situation. The Wap65-1 isoform displayed no significant modulation following LPS injection, with the exception of slight upregulation in the intestine of fish that received $2 \mu \mathrm{g} / \mathrm{g}$ LPS. Conversely, challenge with both 2 and $5 \mu \mathrm{g} / \mathrm{g}$ LPS significantly stimulated the transcription of Wap65-2 isoforms in all three tissues. The maximum Wap65-2 transcript levels induced by the LPS challenge did not differ significantly among the three tissues. Unlike the dose-dependent increase in Wap65-2 transcript levels upon LPS injection in the kidney and spleen, the expression level in the intestine exhibited an inverse relationship with the dose and should be further examined. Overall, the transcriptional responses of mud loach Wap65 genes during bacterial and LPS challenges were largely isoform-specific - the mud loach Wapa65-2 isoform was preferentially activated in most cases regardless of tissue type. This modulation pattern is in accordance with previous studies of other fish species, including catfish (I. punctatus) (Sha et al., 2008), ayu (Plecoglossus altivelis) (Shi et al., 2010) and rockbream (O. fasciatus) (Lee et al., 2014). A similar phenomenon (i.e., Wap65-2-exclusive or preferential activation in response to LPS or bacterial challenge) was also reported in the liver of the mud loach in our previous work, although Wap65-1 was downregulated only slightly during challenges in the intestine, kidney and spleen examined in the present study (Cho et al., 2012). Furthermore, the mRNA expression patterns of mud loach Wap65 genes in response to ET and LPS injection are congruent with the bioinformatic results of this study; the mud loach Wap65-2 promoter, but not Wap65-1 isoform, possesses potential binding motifs targeted by NF-кB. However, several previous studies have also reported either preferential activation of Wap65-1 or little induction of Wap65-2 during immune challenges (Kikuchi et al., 1997; Hirayama et al., 2004; Sarropoulou et al., 2010), indicating the isoform-dependent regulation of fish Wap65 genes to be species-specific.

Mud loaches challenged with polyI:C synthetic viral mimics displayed expression patterns of Wap65 isoforms that differed from those challenged with ET or LPS. Unlike ET and LPS challenges, which resulted in isoform-specific induction of expression (i.e., preferential induction of Wap65-2 in all three tissues), expression of neither isoform was significantly modulated in the intestine and kidney following polyI:C challenge. PolyI:C challenges significantly upregulated both Wap65-1 and Wap65-2 isoforms only in the spleen, in which the maximum levels of induction of Wap65-2 (up to 16-fold) 
were higher than Wap65-1 (5-fold). Transcriptional responses of both Wap65 isoforms during viral challenges (or challenges with polyI:C viral mimics) have been reported by a limited number of studies (Sarropoulou et al., 2010; Lee et al., 2014). The isoform specificity of fish Wap65 gene regulation in response to viral infection has been reported to be species-specific and tissue-dependent; in seabass (Dicentrarchus labrax), Wap65-1 isoform expression is activated in the spleen (but not in the liver) during Nodavirus challenge, whereas Wap65-2 expression is upregulated in the liver but not the spleen during the same challenge (Sarropoulou et al., 2010). On the other hand, rockbreams (O. fasciatus) challenged with rockbream iridovirus (RBIV) exhibited significant induction of Wap65-2 transcripts in kidney, liver and spleen, with the highest induction in the spleen, while Wap65-1 expression was stimulated in the kidney but repressed in the liver and spleen (Lee et al., 2014). Hence, our results regarding the expression patterns of Wap65-2 genes upon polyI:C injection (i.e., significant induction of both Wap65 isoforms only in the spleen) are broadly in agreement with the findings of the two previous studies regarding the main target organ for transcriptional responses of Wap65 genes. However, no generalized pattern of isoformspecific modulations between tissues has been identified, suggesting that further empirical examination of expression upon viral infection should be conducted. A wider range of polyI:C doses should be tested to validate the reproducibility of the spleen-specific modulation of mud loach Wap65 genes (see Nam et al., 2011).

In summary, the genomic organization, including promoter structures, of two mud loach Wap65 isoforms were characterized and their transcriptional responses in the intestine, kidney and spleen to various immune challenges were examined. Both mud loach Wap65 isoform genes showed a conserved exon-intron organization common to other teleostean Wap65 genes; however, the two isoforms displayed differential profiles of stress/immune-related TF binding sites in their regulatory region; a greater number of inflammation-related $\mathrm{TF}$ sites was present in the Wap65-2 isoform. Congruent with promoter characteristics, experimental immune challenges using pathogenic bacteria, LPS or polyI:C induced Wap65-2 transcript levels to a greater degree than the Wap65-1 isoform. Taken together, these data suggest that functional diversification between the two mud loach Wap65 isoforms (i.e., greater involvement of Wap65-2 in the acute phase of inflammation and innate immunity) occurs at the mRNA level in multiple tissue types, and suggests that their modulation patterns are tissue- and stimulant-dependent.

\section{Acknowledgments}

This study was supported by a research grant of Pukyong National University (2014 Year).

\section{References}

Aliza D, Ismail IS, Kuah MK, Shu-Chien AC and Muhammad TST. 2008. Identification of Wap65, a human homologue of hemopexin as a copper-inducible gene in swordtail fish, Xiphophorus helleri. Fish Physiol Biochm 34, 129-138.

Cho YS, Lee SY, Bang IC, Kim DS and Nam YK. 2009. Genomic organization and mRNA expression of manganese superoxide dismutase (Mn-SOD) from Hemibarbus mylodon (Teleostei, Cypriniformes). Fish Shellfish Immunol 27, 571-576.

Cho YS, Kim BS, Kim DS and Nam YK. 2012. Modulation of warmtemperature-acclimation-associated $65-\mathrm{kDa}$ protein genes (Wap 65-1 and Wap65-2) in mud loach (Misgurnus mizolepis, Cypriniformes) liver in response to different stimulatory treatments. Fish Shellfish Immunol 32, 662-669.

Dooley H, Buckingham EB, Criscitiello MF and Flajnik MF. 2010. Emergence of the acute-phase protein hemopexin in jawed vertebrates. Mol Immunol 48, 147-152.

Hayden MS and Ghosh S. 2004. Signaling to NF-кB. Genes Dev 18, 2195-2224.

Hirayama M, Nakaniwa M, Ikeda D, Hirazawa N, Otaka T, Mitsuboshi T, Shirasu K and Watabe S. 2003. Primary structures and gene organizations of two types of Wap65 from the pufferfish Takifugu rubripes. Fish Physiol Biochem 29, 211-224.

Hirayama M, Kobiyama A, Kinoshita S and Watabe S. 2004. The occurrence of two types of hemopexin-like protein in medaka and differences in their affinity to heme. J Exp Biol 207, 1387-1398.

Kikuchi K, Watabe S, Suzuki Y, Aida K and Hakajima H. 1993. The $65-\mathrm{kDa}$ cytosolic protein associated with warm temperature acclimation in goldfish, Carassius auratus. J Comp Physiol B 163, 349-354.

Kikuchi K, Yamashita M, Watabe S and Aida K. 1995. The warm temperature acclimation-related $65-\mathrm{kDa}$ protein, Wap65, in goldfish and its gene expression. J Biol Chem 270, 17087-17092.

Kikuchi K, Watabe S and Aida K. 1997. The Wap65 gene expression of goldfish (Carassius auratus) in association with warm water temperature as well as bacterial lipopolysaccharide (LPS). Fish Physiol Biochem 17, 423-432.

Kim DS, Jo JY and Lee TY. 1994. Induction of triploidy in mud loach (Misgurnus mizolepis) and its effect on gonad development and growth. Aquaculture 120, 263-270.

Kim YO, Park EM, Moon JY, Nam BH, Kim DG, Kong HJ, Kim WJ, Jee YJ and Lee SJ. 2013. Genetic organization of two types of flounder warm-temperature acclimation-associated 65-kDa protein and their gene expression profiles. Biosci Biotechnol Biochem 77, 2065-2072.

Lee SY, Kim BS, Noh CH and Nam YK. 2014. Genomic organization and functional diversification of two warm-temperature-acclimation-associated 65-kDa protein genes in rockbream (Oplegnathus fasciatus; Perciformes). Fish Shellfish Immunol 37, 11-21.

Nakaniwa M, Hirayama M, Shimizu A, Sasaki T, Asakawa S, Shimizu $\mathrm{N}$ and Watabe S. 2005. Genomic sequences encoding two types of medaka hemopexin-like protein Wap65, and their gene expression profiles in embryos. J Exp Biol 208, 1915-1925. 
Nam YK, Cho YS, Lee SY, Kim BS and Kim DS. 2011. Molecular characterization of hepcidin gene from mud loach (Misgurnus mizolepis; Cypriniformes) Fish Shellfish Immunol 31, 1251-1258.

Sarropoulou E, Fernandes JMO. 2011. Comparative genomics in teleost species: knowledge transfer by linking the genomes of model and on-model fish species. Comp Biochem Physiol D Genom Proteom 6, 92-102.

Sarropoulou E, Fernandes JMO, Mitter K, Magoulas A, Mulero V, Sepulcre MP, Figueras A, Novoa B and Kotoulas G. 2010. Evolution of a multifunctional gene: The warm temperature acclimation protein Wap65 in the European seabass Dicentrarchus labrax. Mol Phylogenet Evol 55, 640-649.

Schmittgen TD and Livak KJ. 2008. Analyzing real-time PCR data by the comparative CT method. Nat Protoc 3, 1101-1108.
Sha Z, Xu P, Takano T, Liu H, Terhune J, and Liu Z. 2008. The warm temperature acclimation protein Wap65 as an immune response gene: Its duplicates are differentially regulated by temperature and bacterial infections. Mol Immunol 45, 1458-1469.

Shi YH, Chen J, Li CH and Li MY. 2010. Molecular cloning of liver Wap65 cDNA in ayu (Plecoglossus altivelis) and mRNA expression changes following Listonella anguillarum infection. Mol Biol Rep 37, 1523-1529.

Truksa J, Lee P and Beutler E. 2007. The role of STAT, AP-1, E-box and TIEG motifs in the regulation of hepcidin by IL-6 and BMP-9: Lessons from human HAMP and murine Hamp1 and Hamp2 gene promoters. Blood Cell Mol Dis 39, 255-262.

Wang P and Jin T. 2010. Oct-1 functions as a sensor for metabolic and stress signals. Islets 2, 46-48. 